\title{
Following the Feekes trail - the 'Cereal Disease Atlas'
}

\section{J. C. Zadoks}

Laboratory of Phytopathology, Agricultural University, Binnenhaven 9, 6709 PD Wageningen, Netherlands

Received 13 February 1985; accepted 22 May 1985

Key-words: atlas, barley, cereals, crop loss, damage, Europe, maize, maps, oats, rye, wheat, yield depression

\section{Summary}

In the series of Agro-ecological Atlasses of Cereal Growing in Europe, published by Elsevier, Amsterdam, and Pudoc, Wageningen, Volume III 'Atlas of Cereal Diseases and Pests in Europe' appeared in 1984. The history of the atlas and some of its key features are described. The atlas depicts damage to barley, maize, oats, rye and wheat caused by some seventy harmful agents, among which the major fungal and viral pathogens, and insect and nematode pests. The atlas contains one map for each of 68 pathosystems. All maps show Europe at a scale of about 1:16 000000 . Damage is expressed by a long-term average of yield depression in per mill (i.e. per thousand). Where possible, maps are drawn with isodam lines, lines connecting locations with equal damage. The validity of these historical maps for future situations is discussed.

\section{Introduction}

The late 1950 s were fascinating years for a young scientist. The economy was expanding; everything seemed possible; internationalism ran high. The Dutch wheat scene was dominated by Dr Willem Feekes, internationalist par excellence, who annually covered some 40.000 kilometers in Europe in his big, comfortable car, driving very carefully. With his keen power of observation he saw many queer phenomena which escaped the attention of more sedentary scientists, lacking the opportunity of travel and international comparison. Innumerable were his attempts to design graphs and to draw maps (e.g. Feekes, 1967) in order to systematize his observations. He freely circulated his ideas, graphs and maps among colleagues and scientists, preferably during the merry-making sessions following the day's hard work. Possible explanations for the regional differences observed by Feekes were discussed. As a matter of course, the idea was born to develop a series of Agro-ecological Atlasses of Cereal Growing in Europe.

The idea was as manna to Dr Sim Broekhuizen. Whereas Feekes took to the 


\section{J. C. ZADOKS}

limelight, dominant, brilliant, always generating new ideas but rarely finishing them, the modest Broekhuizen preferred the shadow, permanently writing reports, even when riding in the back-seat of Feekes' car. Broekhuizen added bones and meat to ideas, writing research proposals and reports. The atlas offered Broekhuizen the opportunity to become engaged - once more - in a piece of solid scientific work. He jumped at the occasion, was co-producer of Atlas 1 in 1965 (Thran \& Broekhuizen, 1965), producer of Atlas II in 1969 (Broekhuizen, 1969) and initiator of atlas III in 1968. Broekhuizen decided to undertake the task so that he might complete his career as he began, as a phytopathologist. Serious illness interrupted the work and, upon resumption, Broekhuizen accepted the help of a promising young man, Frans H. Rijsdijk. Unfortunately, Broekhuizen fell ill again and finally succumbed to his illness, leaving behind piles of data from the enquiry, which he had organized to establish a data base from where to construct maps.

To me it was a natural obligation as well as a challenge to take over, and so Frans Rijsdijk continued the work with me. It was a time when storms ran high over the world's universities, and they did not leave the Wageningen Agricultural University untouched. Priorities changed and I had to discontinue the work whereas Rijsdijk nearly completed his part. Ton van der Wal, now Professor A. F. van der Wal, with his considerable knowledge of wheat and formidable energy, stepped in, developing the Atlas nearly into a handbook of wheat pests and diseases. Then, the recession set in, and priorities changed once more. Long delays and a change in commercial prospects killed a fine idea.

Several good publications on cereal pests and diseases appeared (Buhl et al., 1971, 1975; Boerema \& Verhoeven, 1977; Gareth Jones \& Clifford, 1978; Rapilly et al., 1979; Wiese, 1977), but maps remained rare. Very nearly, Atlas III drowned in another wave of turbulence ravaging Dutch universities, but, thanks to the perseverance of the European Cereal Atlas Foundation, the optimism of the then president Mr A. Rutgers, and the always friendly but very persistent pressure of ECAF secretary Dr Wouter Lange, Atlas III survived. By a drastic change in format, Atlas III became manageable again scientifically, technically and commercially. Feekes lived long enough to see the work on Atlas III resumed.

\section{The scientific base of the atlas}

The original idea of the atlas was to indicate the regional distribution of harmful agents, be they fungi, insects, nematodes, or viruses, that affect cereals. As this had been done before, for example in the CMI maps, I considered maps indicating just presence or absence to be neither new nor informative for plant breeders, plant protectors, chemical industry, or governmental agencies. The sheer presence of an unusual insect, reported once by an observant entomologist, gives no information on its harmfulness.

A minimum requirement was to map disease and pest severity, but, whereas the yes-or-no of the distribution map has the merit of apparent precision, the severity maps would be very imprecise due to lack of suitable data. Few countries provided acceptable information, and that for few cereal crops only. Severity estimates are 
notoriously subjective. Even if information of the desired level of accuracy were available, I doubted the value of that information for atlas users, because mean severity tells little about mean crop loss due to the intricacies of damage functions (Zadoks \& Schein, 1979). In addition, severity data can be collected, but even in a map presentation they provide little new information.

So, the bold decision was to map damage. Whereas injury is what we can see in the crop but should not be there, damage is what we do not harvest because of the injury (Zadoks, 1985). Damage is expressed as a fraction, a percentage, or a per mill value of the yield from an injured crop. That yield is, in technical terms, the reference yield. The reference yield should be known, but unfortunately it was not. The complexities of determining a reference yield have been discussed elsewhere (Zadoks \& Schein, 1979). Consequently, we had to accept all damage input data, expressed as per cent, on their face value. Also, we had to accept the impossibility to translate either input or output into kilograms lost per hectare.

The input data were 'units of information'. Every unit of information contained one crop, one harmful agent, one place, and one damage estimate, with some corollary information, all on one punched card. Over 20000 of such units of information were available, in part from the enquiry sent around by Dr Broekhuizen, in part from a search through the literature. The search, made by Pudoc, covered those countries where response to the enquiry was slight to nil, such as several East European countries. Whatever data were available, they were transformed into per cent damage.

Much of the information collected in either way was specific rather than general in nature. It referred to a specific location, crop, cultivar or year. Nearly all of this information reflected the bias of the observer, who had reasons to overestimate or - on the contrary - to underestimate the damage. Some informants saw only insects where fungal diseases must have been present, others saw the inverse. In short, all information received was highly subjective, with the notable exception of some information from the United Kingdom. What to do?

It was decided to eliminate only that information that was blatantly wrong, a very small proportion indeed. All other information received the benefit of the doubt. Every unit of information was given a set of qualifiers. One qualifier weighed the information with respect to age. A second qualifier weighed the information as to its representativeness for either a single locality, an administrative region of the approximate size of a 'climatic subprovince', or a nation. A third qualifier was the climatic subprovince according to Atlas I. These types of information were usually specified in the enquiry and in the literature. The largest weight was given to those units of information that were both of regional value and recent.

Some information was incomplete as severity was indicated in per cent or in words, but not damage. To make the best use of this type of incomplete information the hypothesis was forwarded that, for each climatic subprovince, the various informants should have indicated approximately the same damage. Careful comparison of all units of information from one climatic subprovince with at least one damage specification in per cent, permitted the authors to give at least subjective weights to indications such as 'much infection' and 'medium damage'. The procedure also indi- 


\section{J. C. ZADOKS}

cated which informants systematically deviated from others. Carefully, a routine was developed to evaluate incomplete information and use whatever seemed useful. Every damage estimate or damage description was assigned a ranking number ranging from zero to five, the damage code (DACO). For each pathosystem, a relationship between damage code and damage in per cent was established (Rijsdijk \& Zadoks, 1976).

Being dependent on the benevolence of the informers and of the aptitude of literature researchers, the total data set was lacunary. In contrast, from some climatic subprovinces, where research institutes and/or plant breeding stations were concentrated, an abundance of data was received, so that procedures could be checked for some climatic subprovinces at least.

Information was received about well over 300 pairs of host and harmful agent 300 pathosystems, to use Robinson's terminology (Robinson, 1976). For most pathosystems the information was so scanty that no mapping could be done at all. For a hundred pathosystems maps could be made, using one value, the weighted mean annual damage (MAD), per climatic subprovince. Usually, northwest Europe was well covered with data, whereas few or no data were available from the Mediterranean area and eastern Europe. Only pathosystems with data for at least 20 climatic subprovinces were considered for publication. Where possible, but only where data for at least 30 climatic subprovinces were available, the lines of equal damage were drawn. These lines of equal damage were called 'isodams'. An overview of the procedure is given in Atlas III, Fig. 2 (Zadoks \& Rijsdijk, 1984). However careful the procedure was, it did not (and should not) preclude the imprint of a highly enthousiastic informant from southeast Scotland. This area seemingly has more and more severe insect pests than the surrounding areas.

Rijsdijk developed a computer program for automatic plotting of isodams. The resulting plots were used as guidelines, but isodams were hand-drawn with due consideration of agro-ecological factors. In several cases, the authors did not feel justified to draw isodams. If so, the original MAD values per climatic subprovince were presented. The end result was an atlas containing 38 isodam maps and 31 MAD maps. One pathosystem was shown in both modes (Maps 40 and 41) for the purpose of comparison.

\section{The maps}

Examination of isodam maps shows few common patterns. Relationships between isodam maps and climatic maps of Atlas I remain hidden. Examination of individual disease maps and careful comparison with the maps of Atlases I and II is indicated taking into account all known details of the pathogen's life cycle.

A provisional examination of the isodam map for yellow rust of wheat (Puccinia strifformis) is a good example. Isodams are at $2 \%$ distances. High density of isolines indicates steep gradients. Danger areas appear as in Switzerland plus Bavaria, Czechoslovakia, Greece (Thessaloniki), and the Caucasus. The well-known AngloDutch area and the Rumanian coastal area are less prominent. The map is clearly influenced by the 1961 epidemic (Zadoks, 1965), which hardly affected the Nether- 
lands. The relation between the Grecian and Turkish rust areas remains hidden as Turkey was not incorporated in the analysis. The Iberian data hint to what might happen; a devastating yellow rust epidemic scourged Andalucia in 1979 (Nagarajan et al., 1984). Judging in toto, the map of $P$. striiformis on wheat provides a fair picture of the European scene, though with a recognizable effect of the specific 1961 situation. That situation was induced by a Europe-wide favourable weather pattern and coloured by regional and specific cultivar-race interactions.

The map for brown rust of wheat (Puccinia recondita) contrasts with that for yellow rust. Differences between isolines are not $2 \%$ but $1 \%$. Even so, there are no steep gradients. There are a few danger areas, different from those for yellow rust, but they are not very marked. $P$. recondita on rye shows a vaguely similar pattern, though somewhat more distinct, with comparable danger areas in southern Scandinavia and in the upper Danube plains.

The powdery mildew (Erysiphe graminis) also varies according to the host. For barley, a clear pattern appears, confirmed as approximately correct by several knowledgeable colleagues. The pattern, with emphasis on NW Germany and surroundings, differs from the patterns for $P$. striiformis and $P$. recondita. The distinct pattern for powdery mildew of barley contrasts sharply with the non-pattern for mildew of wheat. This non-pattern seems to be fairly characteristic for the wheat mildew situation in the 1960s.

An interesting but aborted attempt was to compare the real damage situation with the potential damage situation, as calculated by a simulation model, using the weather information from Atlas I and epidemiologic data. The result is a wide discrepancy between potential damage and real damage (Rijsdijk \& Zadoks, 1979). The reason for the discrepancy may be sought in the imperfection of our knowledge, but also - and in my opinion primarily - in the positive contribution of resistance breeding.

What can happen when resistance breeding fails, or - better - when it is omitted, was demonstrated in a most bitter way by the $1978 / 1979$ yellow rust epidemics in the west-Mediterranean basin (Nagarajan et al., 1984). High-yielding cultivars with little resistance had been introduced into Tunesia, eastern Algeria and southern Spain, not typical danger areas of yellow rust. But the improbable happened. Long-term weather became suitable for yellow rust build-up so that in 1978 a severe epidemic ravaged Tunesia, eastern Algeria, and the Italian mountain areas. The epidemic continued in 1979 when it hit Andalucia in southern Spain. Remnants were visible in Italy and Algeria, but not in Tunesia, where the whole area had been planted with a resistant local cultivar. Neglect of resistance was punished severely indeed.

Needless to remark that this story on the yellow rust epidemic in the western Mediterranean basin illustrates the point that damage maps, even long-term average damage maps, inevitably reflect typical situations of specific periods. Only when this limitation is duly considered, generalization of mapping results is permitted within limits.

Let me add one map characteristic which refers to mountain areas. These were excluded from descriptions in Atlases I and II because of their great ecological vari- 
ation over short distances. That great ecological and agricultural variation apparently is conducive to some harmful agents such as loose smut (Ustilago nuda) of wheat, which shows an alpine damage pattern.

There is no easy way to categorize the maps on the basis of regional distribution characteristics or on an ecological basis. The damage distribution of yellow rust of wheat $(P$. striiformis) is linked to a rather specific 'window' of moisture/temperature combinations which appears to be present in different parts of Europe, unpredicted by any of the agro-meteorological maps from the preceeding two atlasses. The general conclusion must be that only now we can begin to explain the distribution of damage as given in Atlas III (Zadoks \& Rijsdijk, 1984) by using the agroecological information given by Atlases I and II, but that explanation is a new and not-so-easy job (Rijsdijk \& Zadoks, 1979).

\section{A value judgement?}

How should we consider the end results of all efforts, Atlas III? Paraphrasing the modern computer adage 'rubbish in, rubbish out' I should say 'opinions in, opinions out'. The input material consisted of a few measured values, of many educated guesses, and mostly of opinions, biased opinions without doubt. Opinions, even of specialists, are such that - not infrequently - total damage estimated by all relevant specialists adds up to over one hundred per cent (Ogawa, personal communication). These opinions were sifted, qualified, compared and weighted, and in doing so they were transformed into input data. The rest was mainly a matter of a few computer algorithms leading over one MAD value per climatic subprovince to a draft isodam map. The final maps were redrawn by hand. So before the input and after the output of the data many actions were taken, directed by the knowledge and intuition of the scientist, but definitely subjective. The resulting maps must be considered as opinions again, the educated opinions of the authors. At some stage, a number of pilot maps were subjected to the opinion of internationally reknown specialists (European and Mediterranean Cereal Rust Conference, Interlaken, 1976). They generally agreed, but that confirmation is - again - subjective.

By subjecting the input information to a rather rigorous protocol, that is known, repeatable, open to debate and improvement, the 'input information' was transformed into 'input data'. If anybody would want to do it differently, he could - at least in principle - do it all over again to see whether his input data and/or final maps would materially differ from those presented here. The structured way of information and data processing is the 'added value', that makes the authors believe that their opinion on damage is not far from the truth. Atlas III reflects the situation of the late 1960s. It reflects the situation before the great intensification of cereal growing spread over Europe, stimulated by high technology, by high inputs of energy, fertilizers and pesticides, and by high prices on protected markets. With the notable exception of barley net blotch and wheat aphids, few pathosystems seem to have changed profoundly. If so, Atlas III has some value for present and future days, and the dreams of the two great cereal specialists, Feekes and Broekhuizen, have been fulfilled. 


\section{References}

Boerema, G. H. \& A. A. Verhoeven, 1977. Check-list for scientific names of common parasitic fungi. Netherlands Journal of Plant Pathology 83: 165-204.

Broekhuizen, S. (Ed.), 1969. Agro-ecological atlas of cereal growing in Europe. II. Atlas of the cerealgrowing areas in Europe. Pudoc, Wageningen, and Elsevier, Amsterdam/London/New York, 60 maps and $157 \mathrm{pp}$. of text.

Buhl, C. \& F. Schütte, 1971. Prognose wichtiger Pflanzenschädlinge in der Landwirtschaft. Paul Parey, Berlin, 364 pp.

Buhl, C., H. Weidner \& H. Zogg, 1975. Krankheiten und Schädlinge an Getreide und Mais: ein Bestimmungsbuch. Eugen Ulmer, Stuttgart, $451 \mathrm{pp}$.

Feekes, W., 1967. Phytopathological consequences of changing agricultural methods. Netherlands Journal of Plant Pathology 73 (Suppl. 1): 97-115.

Gareth Jones, D. \& B. C. Clifford, 1978. Cereal diseases, their pathology and control. BASF, Hadleigh, U.K., 279 pp.

Nagarajan, S., J. Kranz, E. E. Saari, G. Seiboldt, R. W. Stubbs \& J. C. Zadoks, 1984. An analysis of the 1978 epidemic of yellow rust on wheat in Andalusia, Spain. Zeitschrift für Pflanzenkrankheiten und Pflanzenschutz 91 (2): 159-170.

Rapilly, F., Y. Laborie, P. Eschenbrenner, E. Choisnel \& F. Lacroze, 1979. La prévision du piétinverse sur blé d'hiver. Perspectives agricoles: 30-37.

Robinson, R. A., 1976. Plant pathosystems. Springer, Berlin, 184 pp.

Rijsdijk, F. H. \& J. C. Zadoks, 1976. Assessment of risks and losses due to cereal rusts in Europe. Proceedings of the 4th European and Mediterranean Cereal Rust Conference (Interlaken): 60-62.

Rijsdijk, F. H. \& J. C. Zadoks, 1979. A data bank on crop losses: first experiences. EPPO (European and Mediterranean Plant Protection Organisation, Paris) Bulletin 9: 297-303.

Thran, D. \& S. Broekhuizen, 1965. Agro-ecological atlas of cereal growing in Europe. I. Agro-climatic atlas of Europe, Pudoc, Wageningen, and Elsevier, Amsterdam/London/New York, 125 maps and 38 pp. of text.

Wiese, M. V., 1977. Compendium of wheat diseases. American Phytopathological Society, St. Paul, $106 \mathrm{pp}$.

Zadoks, J. C., 1965. Wheat rust epidemiology in Europe. FAO Plant Protection Bulletin 13: 97-108.

Zadoks, J. C., 1985. On the conceptual basis of crop loss assessment: threshold theory. Annual Review of Phytopathology 23 (in press).

Zadoks, J. C. \& F. H. Rijsdijk, 1984. Agro-ecological atlas of cereal-growing in Europe. Vol. III. Atlas of cereal diseases and pests in Europe. Pudoc, Wageningen, $169 \mathrm{pp}$.

Zadoks, J. C. \& R. D. Schein, 1979. Epidemiology and plant disease management. Oxford University Press, New York, $427 \mathrm{pp}$. 